\title{
Effect of Heat Treatments on the Mechanical Properties of DIN 50Cr3 Spring Steel
}

\author{
O. Elzahed ${ }^{*}$, M.Tolba Sallam ${ }^{\dagger}$, K. Almazy ${ }^{\ddagger}$ and M.M.Osman ${ }^{\S}$
}

\begin{abstract}
This experimental study was conducted to investigate the optimum combination of properties between ductility and toughness from one hand and strength and hardness from the other hand of a commercial grade of light duty spring steel DIN 50Cr3 having a chemical composition of $(0.25 \% \mathrm{C}, 0.8 \% \mathrm{Cr}, 0.79 \% \mathrm{Mn}, 0.2 \% \mathrm{Si})$.

A heat treatment process by quenching in both oil or water followed by tempering cycles at different temperatures for various tempering times was adopted. The proper austenitization temperature was found to be $870{ }^{\circ} \mathrm{C}$. The structure after quenching reveals the formation of martensite with limited amount of retained austenite. Tempering was performed at different temperatures from 250 to $550^{\circ} \mathrm{C}$ for prolonged times ranging from $1 \mathrm{hr}$ up to $3 \mathrm{hr}$.

It was found that oil quenching provides sensibly higher elastic properties than water quenching particularly in the low tempering temperature range. More ever, by increasing the tempering temperature and time ultimate tensile strength, hardness were gradually decreased while ductility remarkably improved. The resultant microstructure after tempering was characterized by a tempered martensitic structure with simple and complex dispersed carbides. Optimum elastic properties were delivered out of this steel after tempering at $450^{\circ} \mathrm{C}$ for $1 \mathrm{hr}$.
\end{abstract}

Keywords: Water quench, Oil quench, Tempering, Martensite, Retain austenite, Baitenite.

\section{Introduction}

Springs are elastic bodies which are used to store mechanical energy. They can be twisted, pulled, or stretched by some force. They can return to their original shape when the force is released. In other words it is also termed as a resilient member. Springs are usually made of spring steels. These steels are generally low alloy, medium carbon or high carbon steels with relatively very high yield strength [1]. There are a large number of spring designs in every day usage. When a spring is compressed or stretched from its resting position, it exerts an opposing force approximately proportional to its change in length this approximation breaks down for larger deflections.

Small springs can be formed in the prehardened state, while larger springs are formed in the annealed state then hardening is carried out after fabrication. There are several types of springs such as spiral torsion spring, helical springs, torsion bars and... etc. Among this numerous types of springs leaf springs are considered an important candidate for heavy trucks and military vehicles suspensions.

\footnotetext{
*Egyptian Armed forces, Egypt; osamaelzahed@mtc.edu.eg

$\dagger$ Prof. Dr. Eng. Egyptian Armed forces. Egypt.

$\$$ Dr. Eng. Egyptian Armed forces, Egypt.

$\S$ Dr. Eng. Egyptian Armed forces, Egypt.
} 
Most springs obey Hooke's law, which states that the force with which the spring pushes back is linearly proportional to the distance from its equilibrium length within their elastic limit. There for the objective of most of heat treatments applied to this type of steels is mainly directed to enlarge the elastic range and to increase the ratio between yield and ultimate strength [2].

Generally, quenching and tempering are a well-established means to produce strengthening in these types of steels. This is achieved mainly due to the martensitic structure produced by quenching and the subsequent precipitation of a fine dispersion of alloy carbides during tempering [3,4]. To attain the highest level of strength in steel, the martensite structure is rarely used in non-tempered conditions because the high internal stresses associated with the transformation cause the material to be lacking in ductility. The change in microstructure and strength after the heat treatment process depends on the cooling rate obtained during quenching. Oil quenching, with lower quench severity, is generally more recommended than water quenching, since water impart particularly high quench severity which provides structures containing intensive internal stresses and micro cracks. Today oil quenched and tempered springs are widely used for heavy duty spring where high mechanical properties are the main design driver.

However, apart from the effect of tempering temperature, the strength of the martensitic structure is dominated by the carbon content and the $\left(\mathrm{M}_{\mathrm{s}}-\mathrm{M}_{\mathrm{F}}\right)$ temperature range $[5,6]$. In the case of low-carbon martensite, the martensite units form in the shape of lath, grouped into larger sheaves or packets. Its substructure consists of high densities of dislocations arranged in cells, and is superficially similar to that developed in iron by a heavy cold-working process. In the case of high-carbon steels and iron alloys with Ms below the ambient, their structure is plate martensite, which consists of very fine twins with a spacing of about $50 \mathrm{~A}^{\circ}$. Their crystal structure may be either (BCT) or (BCC). However, in the case of medium-carbon steels, since they may contain a mixture of lath and plate martensite, their structure is more complicated. These results also indicate that the mechanical behavior of a quenched-and-tempered steel depends strongly on its microstructure. Thus, the study of effects of the microstructure and dislocation structure of a steel on its strength, ductility and fracture characteristics is of great importance from the viewpoint of both theory and practice [7].

Untemper martensitic steel, while very hard, is too brittle to be useful for most application. These applications require that quenched part must be tempered. Tempering consists of heating steel below the lower critical temperature $A_{1}$ from 200 up to $650^{\circ} \mathrm{c}$, depending on the desired applications, to impart toughness and ductility.

Precise control of time and temperature during the tempering process is crucial to achieve the desired balance of mechanical and structure properties. Low tempering temperatures may only relieve the internal stresses, decreasing brittleness while maintaining the majority of the hardness. Higher tempering temperatures tend to produce greater reduction in the hardness, sacrificing some yield and tensile strength for an increase in elasticity, ductility and toughness. The structure changes that take place during tempering can be summaries as follows [8]:

1 - Up to $200^{\circ} \mathrm{C}$ : carbon diffusion allows the formation of lower carbon martinsite with decreased tetragonality, and precipitation of $\varepsilon$ (epsilon) carbide $\mathrm{Fe}_{2.4} \mathrm{C}$ and some other complex carbides.

2- From $200^{\circ} \mathrm{C}$ to $300^{\circ} \mathrm{C}$ : Decomposition of retained austenite to bainite or ferrite.

3- From $250^{\circ} \mathrm{C}$ to $350^{\circ} \mathrm{C}$ : Formation of plate cementite with almost complete loss of tetragonality of martensite and dissolution of $\varepsilon$ carbides.

4- Form $350^{\circ} \mathrm{C}$ up to $650^{\circ} \mathrm{C}$ : Coarsening and spherodization of cementite along with recovery and recrystallization of ferrite. 


\section{Experimental Procedures}

\section{A. Material Used}

The material used in this study is DIN 50Cr3 spring steel with chemical composition, verified by using X-Ray florescence and spark emission spectroscopy, shown in table I:

Table I The chemical composition of the DIN $50 \mathrm{Cr} 3$ spring steel

\begin{tabular}{|c|c|c|c|c|}
\hline $\mathrm{Fe}$ & $\mathrm{C}$ & $\mathrm{Si}$ & $\mathrm{Mn}$ & $\mathrm{Cr}$ \\
\hline $\mathbf{9 7 . 9 6 1 \%}$ & $\mathbf{0 . 2 5 1 \%}$ & $\mathbf{0 . 2} \%$ & $\mathbf{0 . 7 8 8} \%$ & $\mathbf{0 . 8} \%$ \\
\hline
\end{tabular}

This material was received in the form of stripes having a width of $60 \mathrm{~mm}$ and a thickness of $6 \mathrm{~mm}$, in the annealed state.

\section{B. Specimen Preparation}

Standard specimens were prepared with the required dimensions for tensile and hardness measurements. The shape and dimensions of these standard specimens were chosen according to ASTM E8 standard, and illustrated in Fig 1. These tensile standard specimens were precisely machined to the indicated dimensions using a laser cutting machine type "Trulaser 3030", shown in fig.2.

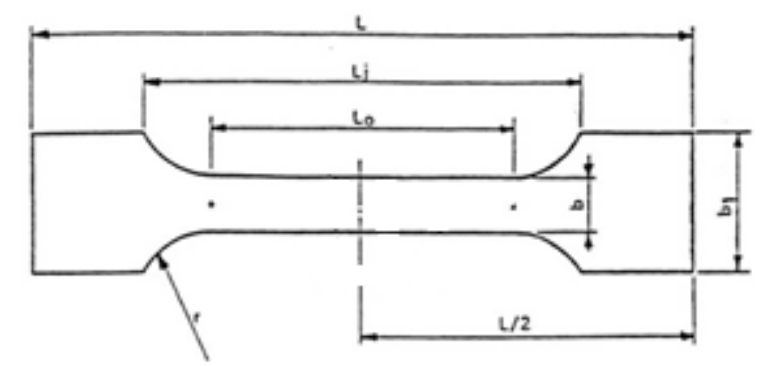

\begin{tabular}{|c|c|c|c|c|c|c|}
\hline $\mathrm{L}$ & $\mathrm{L}_{\mathrm{i}}$ & $\mathrm{L}_{\mathrm{o}}$ & Thickness $(\mathrm{t})$ & $\mathrm{r}$ & $\mathrm{b}$ & $\mathrm{b}_{1}$ \\
\hline $120 \mathrm{~mm}$ & $100 \mathrm{~mm}$ & $45 \mathrm{~mm}$ & $6 \mathrm{~mm}$ & $76 \mathrm{~mm}$ & $7.5 \mathrm{~mm}$ & $10 \mathrm{~mm}$ \\
\hline
\end{tabular}

Fig. 1 Shape and dimensions of the used tensile test specimen
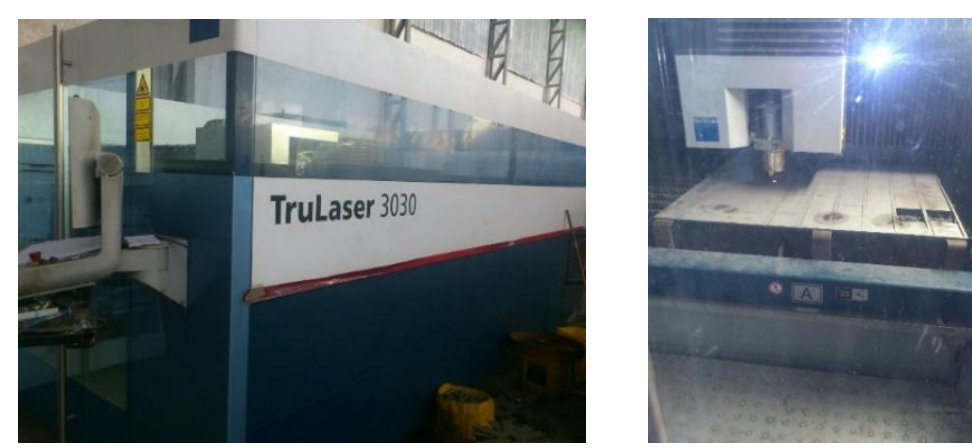

Fig. 2 Laser cutting machine type (Trulaser 3030) 


\section{Heat Treatment Procedure}

During all heat treatment cycles applied on the standard manufactured specimens heating was carried out in open air electric furnace with max temperature $1100^{\circ} \mathrm{c}$. The different applied heat treatments were classified into three groups. The first group aimed at exploring the proper austenitization temperature of this steel, where different specimens were heated to various temperatures in the austenitic range, namely $750,800,850,870,900^{\circ} \mathrm{C}$ for $1 \mathrm{hr}$, followed by direct quenching in oil. The second group was directed to compare between oil and water as quenching medium where different specimens were heated to, a predetermined, proper austenitization temperature and cooling in both cooling medium. The third group was targeted the determination of the optimum tempering parameters (temperature and time). Temperature was varied during tempering from $250^{\circ} \mathrm{C}$ to $550{ }^{\circ} \mathrm{C}$, while time of holding was $1 \mathrm{hr}, 2 \mathrm{hr}$ and $3 \mathrm{hr}$.the applied heat treatment cycles are shown in fig. 3

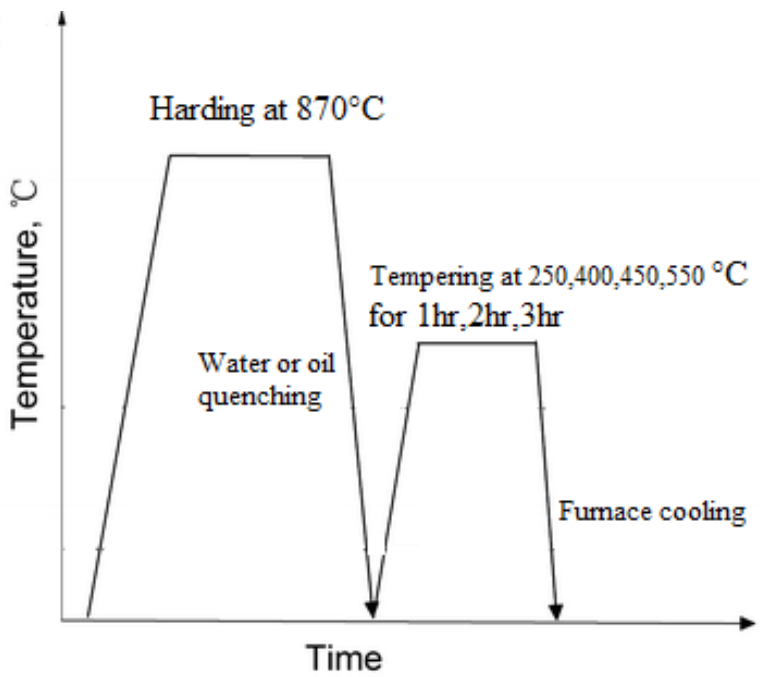

Fig. 3 Heat treatment cycles applied on DIN $50 \mathrm{Cr} 3$ spring steel

Austenitization temperature for steel with less than 0.77 carbon percentage is (30-50) above Ac $\neg 3$, in this study material heated to temperature $870^{\circ} \mathrm{c}$. The total heating time should be just enough to attain uniform temperature through the section of the part to enable not only the completion of phase transformation, but also to obtain homogeneous austenite. It should not be longer to cause grain growth, oxidation, and decarburization. Therefore, the steel must be held at the hardening temperature as short a period of time as possible, generally calculated on the basis of one hour per inch of wire diameter [9]. Moreover, measures should be taken to prevent decarburization, though they are the simplest ones, such as covering the bottom of the furnace with charcoal or used carburizing compound.

After soaking at that hardening temperature, the steel specimen must be cold quenched at a rate faster than its critical cooling rate to attain martensite. After holding for the desired length of time in the hardening temperature, specimens are taken out for cooling in water and oil, the oil should have a good fluidity to increase heat transfer rate and it should be free from water.

The final step of this heat treatment cycle is tempering. Tempering is the process of heating the hardened steel to a temperature maximum up to lower critical temperature (A1), soaking at this temperature, and then cooling, normally very slowly. In this study tempering takes place at different temperature $250,400,450,550^{\circ} \mathrm{C}$ at various times $1 \mathrm{hr}$., $2 \mathrm{hr}$. and $3 \mathrm{hr}$.at every tempering temperature the material heated to the desired temperature and then leaves to cool in the furnace. The desired properties and structures depend on tempering temperature and time. 


\section{Mechanical Evaluation}

The heat treated specimens were further subjected to mechanical evaluation by Appling standard tensile and hardness tests. The tensile test was carried out using electromechanical tensile testing machine type (Galdabini) model ( 1000 ) with maximum loading capacity 100 $\mathrm{KN}$. Tensile specimens were loaded by a quasi-static strain rate of $10^{-3} \mathrm{~s}^{-1}$. The hardness test was carried out using Rockwell hardness testing machine type (kemet) model (Gt254 ). The indenter used was a diamond cone with apex angle $120^{\circ}$. Indents were made on the polished surfaces using a $150 \mathrm{~kg}$ load for HRC scale and $10 \mathrm{sec}$ dwell time.

\section{E. Microstructure and Fracture Evaluation}

Metallographic samples from all heat treatment conditions were prepared using series of emery papers of 100,280,400,600 and 1200 and etched in 4\% NITAL in order to reveal the different microstructures. Optical microscope type (BIOBASE) with different magnifications were used to evaluate and study the evolution of the obtained structure. Tensile fractures were determined using scanning electron microscope type ZIESS model (1386).

\section{Results and Discussion}

\section{A. Determination of the Proper Austenitization Temperature}

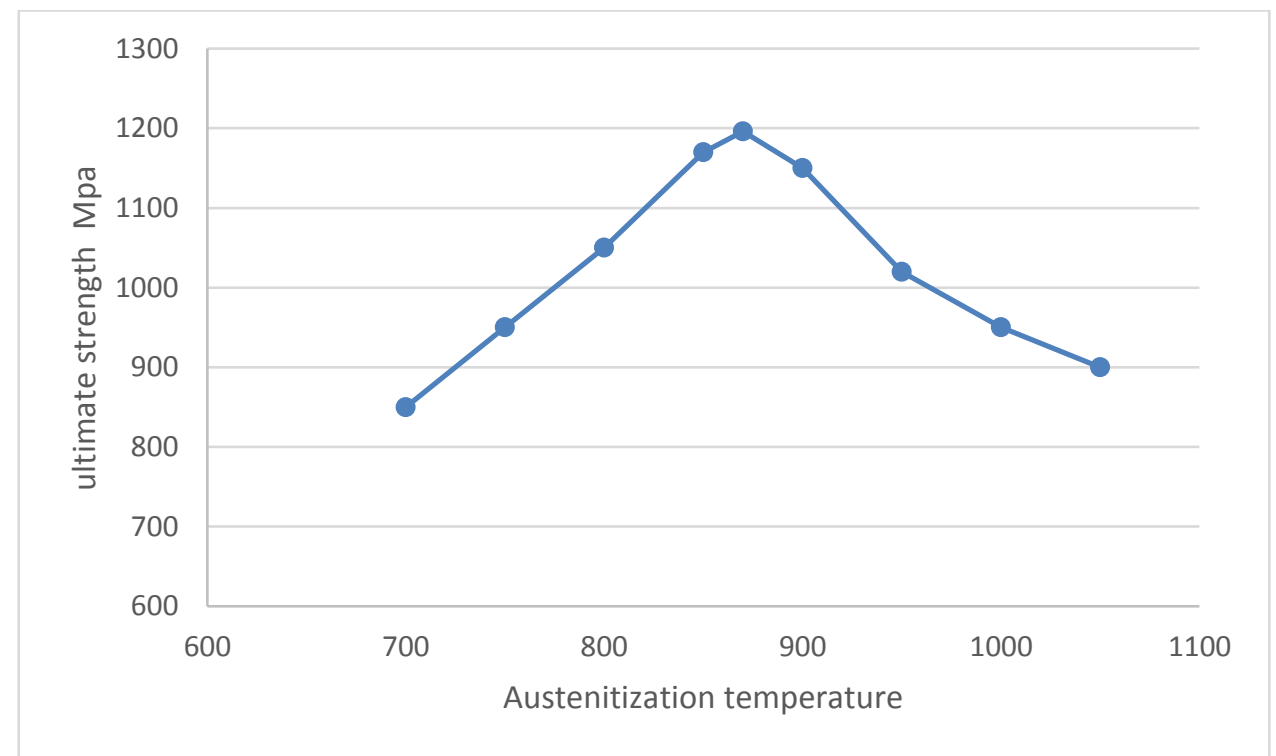

Fig. 4 Effect of austenitization temperature on ultimate strength

Figure 4 illustrates the variation of the ultimate tensile strength of tested specimens austenitizied at different temperatures and quenched in oil. We can note that at low austenitization temperature the obtained ultimate tensile strength is relatively low. By increasing the austenitization temperature the obtained ultimate tensile strength after quenching in oil increases gradually to attain a maximum value of $1196 \mathrm{Mpa}$ at $870^{\circ} \mathrm{C}$, for higher austenitization temperatures the values of ultimate tensile strength decreases drastically by about $20 \%$ of its maximum value.

When austenitization temperature is relatively low it does not permit proper diffusion and homogenization of carbon and alloying elements on the austenitic phase. On the contrary the very high austenitization temperature, in spite that it allows satisfactory homogenization, it provides coarse structure leading to inherently coarse martensite after cooling to room temperature, with very limited ductility and toughness. Furthermore high temperature 
austenitization can drive also to excessive oxidation and decarburization with drastic effect on mechanical properties [9].

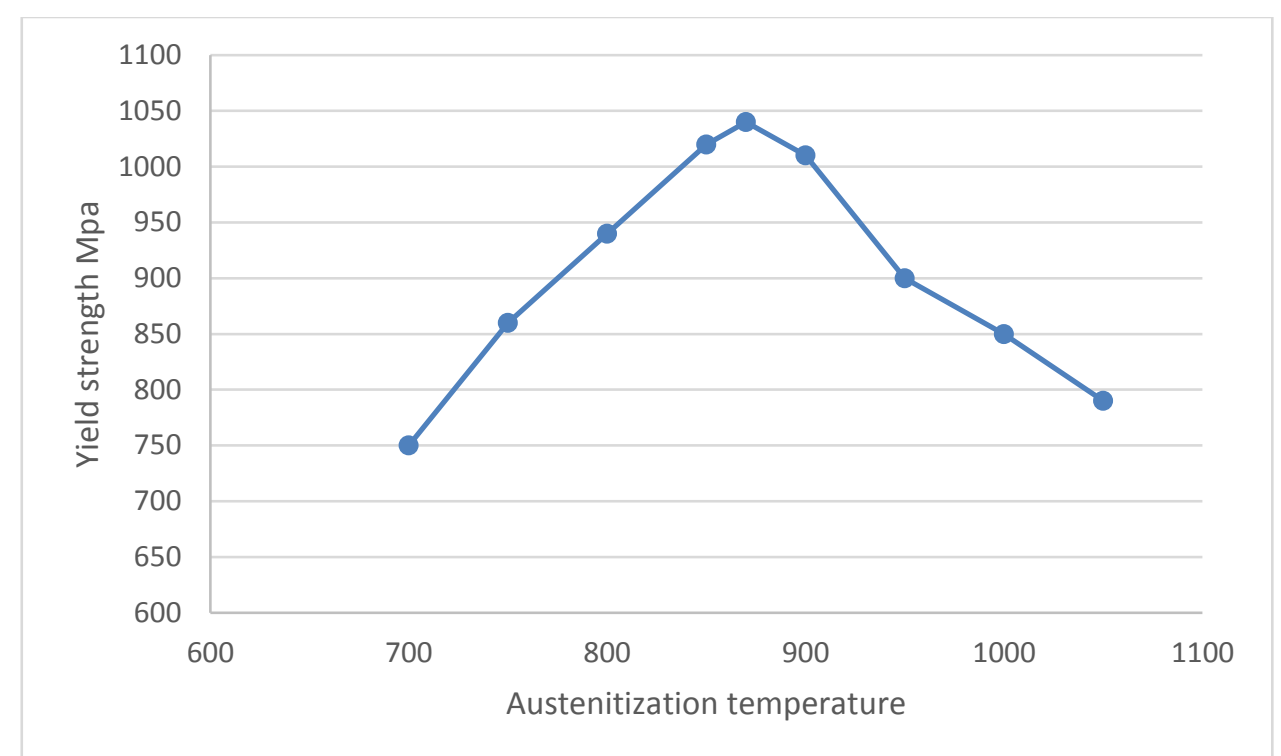

Fig. 5 Effect of austenitization temperature on Offset yield strength

The evolution of the offset yield strength of this spring steel as a function of austenitization temperature is illustrated in fig 5.we can observe very similar behavior to that obtained for ultimate tensile strength were a maximum value of (1040) Mpa at the same temperature $870^{\circ} \mathrm{C}$.

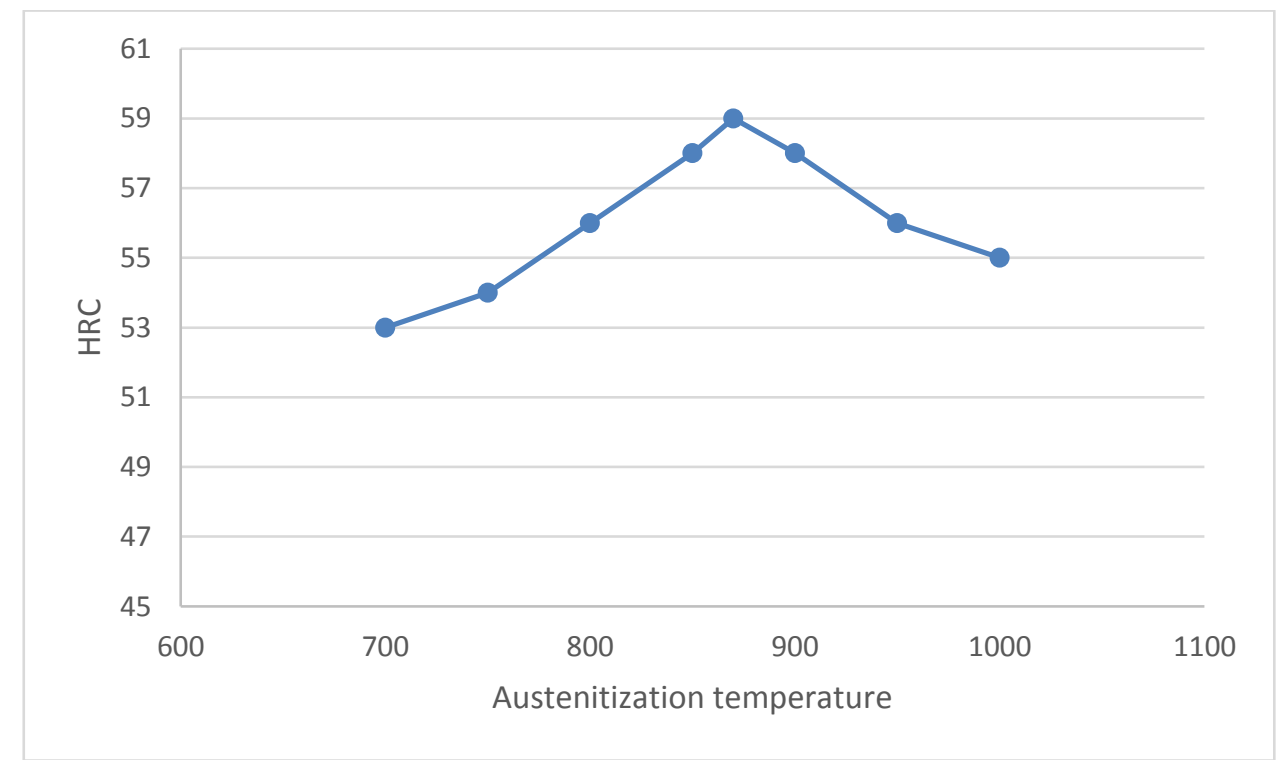

Fig. 6 Effect of austenitization temperature on hardness

Figure 6 demonstrates the variation of Rockwell hardness $\mathrm{HR}_{\mathrm{C}}$ with austenitization temperature we can note that a maximum hardness can also be obtained at $870^{\circ} \mathrm{C}$ which confirms that this temperature is the optimum experimental austenitization temperature. On the hand we can clearly observe that at the higher austenitization temperature the values of hardness drop in a very moderate approach. In fact hardness measurements is less sensitive to the coarsening of grain structure compered to ultimate and yield strength measurements during a tensile test. Plastic deformation in the course of hardness indentation is much localized compared to the bulk plastic deformation that takes place in specimens of the tensile test [10]. 
On the other hand, several efforts has been done to predict this proper austenitization temperature by the determination of the critical transformation temperature to obtain full austenitic structure $A_{\mathrm{C} 3}$ using some empirical equations based upon the alloy chemical composition. One of the most currently used equation published by ASTM standard [11] was as follows:

$\mathrm{Ac}_{3}=910-203 \sqrt{\mathrm{C}} \%+44.7 \mathrm{Si} \%-15.2 \mathrm{Ni} \%+31.5 \mathrm{Mo} \%+104 \mathrm{~V} \%+13.1 \mathrm{~W} \%-30 \mathrm{Mn} \%$ $+11 \mathrm{Cr} \%+20 \mathrm{Cu} \%-700 \mathrm{P} \%-400 \mathrm{Al} \%-120 \mathrm{As} \%-400 \mathrm{Ti} \%$

According to this equation the critical temperature $\mathrm{A}_{\mathrm{C} 3}$ for this type of spring steels is a range from 800 to $810^{\circ} \mathrm{C}$, consequently the proper austenitization temperature is about $850^{\circ} \mathrm{C}$. In spite of that the difference between the values of the proper austenitization determined empirically and experimentally is apparently small but still having a sensible effect on the obtained mechanical properties. This proves that empirical equations can only be taken as a guide but we should rely upon the trusted experimental results.

\section{B. Selection of the Quenching Medium}

Quenching of this category of low alloy spring steel usually carried out in water, oil or salt paths. The cooling rate of the heat treated object depends on many factors like size, composition, initial temperature, and the final required mechanical properties [12]. In our case high hardness, strength with reasonable ductility are the main objectives. Water quenching is usually used for different grades of steels in spite that it does not give good results with some alloyed steels. Water absorbs large quantity of atmospheric gases, and when a hot piece of metal is quenched, these gases has a tendency to form bubbles on the surface of the metal which tend to collect on roots and recesses causing soft spots that later lead to cracking or warping[13]. Oil quenching is preferred for majority of steels since it provides the required hardness and strength and in the same time it maintains a reasonable ductility and toughness. Oil quenching is characterized by slower rate of cooling than water and salt paths.

The comparison between the effect of quenching in water and in oil, on the mechanical properties, for the adopted spring steel was carried out by austenitizing different specimens at the same temperature $870^{\circ} \mathrm{C}$ for $1 \mathrm{hr}$, followed by quenching in either water or oil. Fig. 7, 8 elucidate the obtained tensile Stress-Strain curves on standard specimens quenched in both media. We can clearly note that the values of ultimate tensile strength, in case of oil quenching, is slightly lower than that obtained in case of water quenching by only about $16 \%$. On the contrary ductility is sensibly higher by about $50 \%$. 


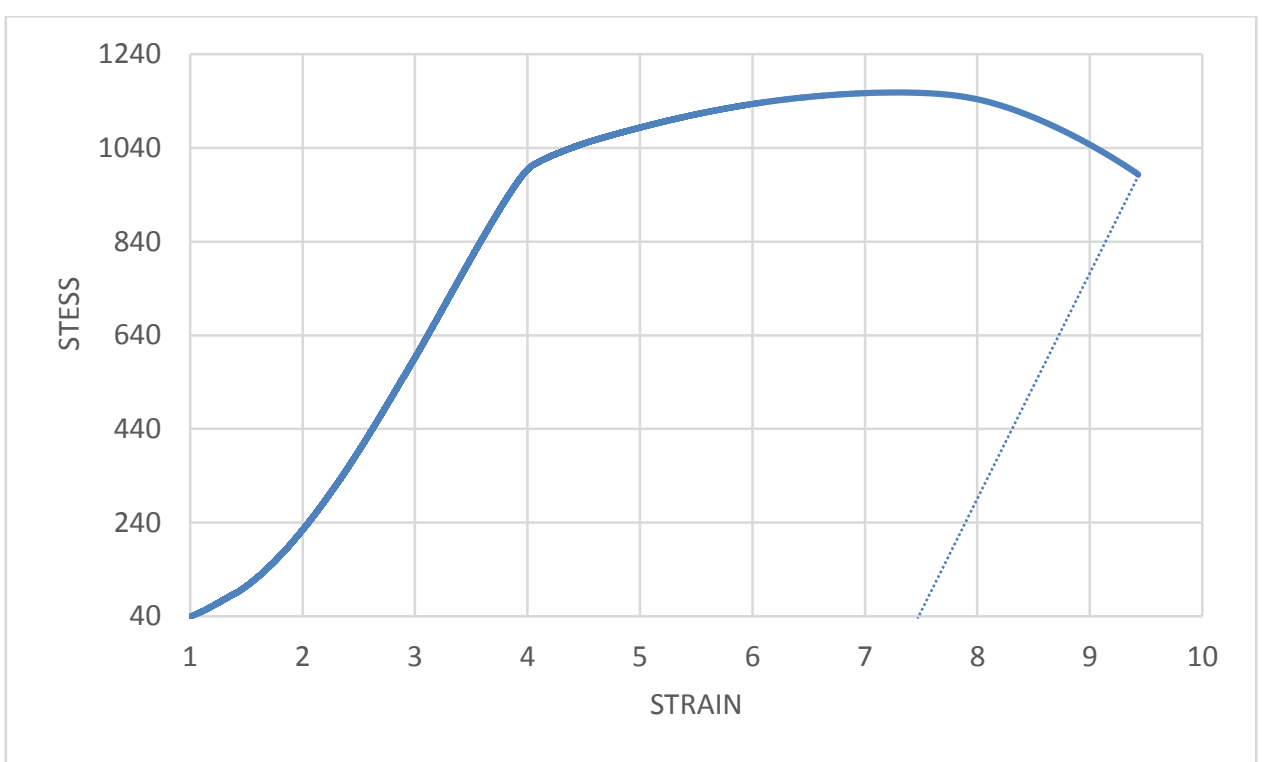

Fig.7 Tensile Stress- Strain curve for the standard oil Quenched specimen of $50 \mathrm{Cr} 3$ spring steel

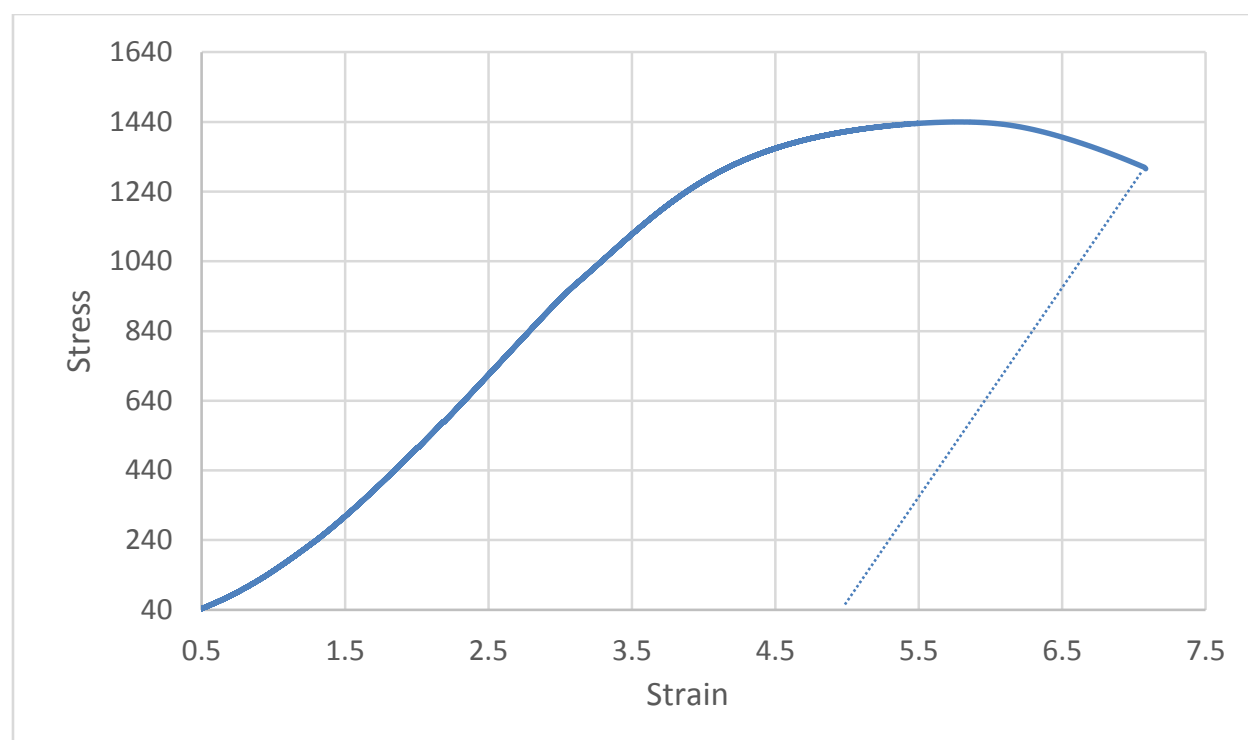

Fig.8 Tensile Stress- Strain curve for the standard water Quenched specimen of $50 \mathrm{Cr} 3$ spring steel

Moreover, Rockwell hardness test (HRC) was carried out on different specimens quenched from the same temperature $870^{\circ} \mathrm{C}$ in both water and oil. The obtained average values of hardness where $62 \mathrm{HRC}$ for water quenched specimens while it was only 58 HRC for those quenched in oil, with a difference of about $6 \%$. Furthermore, the study of the fracture surface of these specimens quenched in either water or oil, shown in Figs.9, 10, revealed the existence of dominating brittle intergranuler fracture mechanism on water quenched specimens, and the existence of mixed modes of dimpled ductile and intergranuler brittle mechanisms on oil quenched specimens. In fact, these obtained fracture modes translate the higher severity of water as a cooling medium providing lower ductility and toughness and manifesting embrittlement of the obtained structure. 


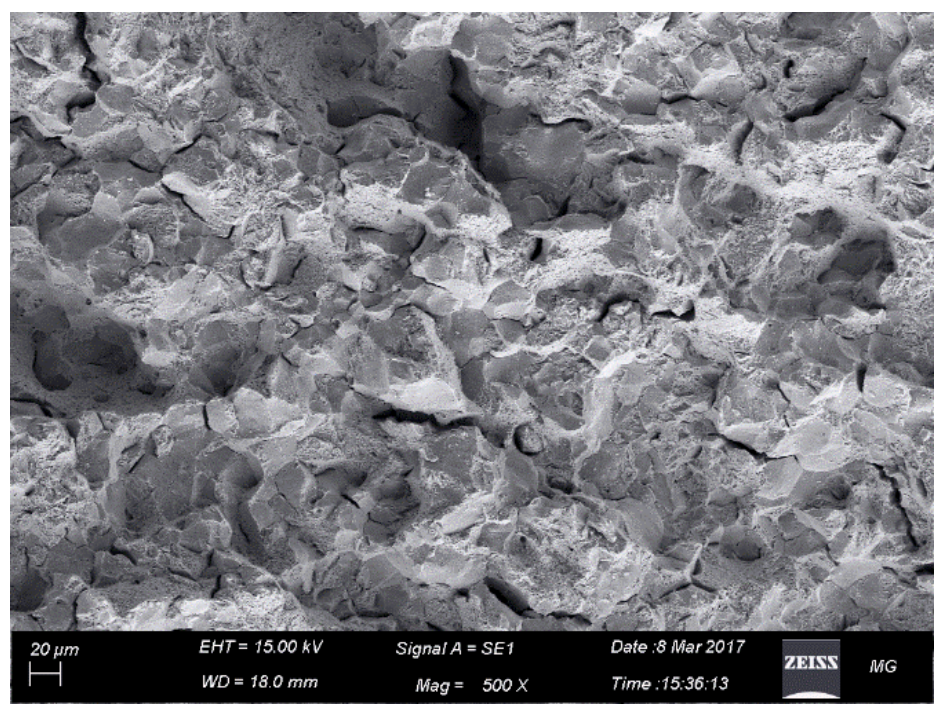

Fig.9 Tensile fracture surface of water quenched specimens

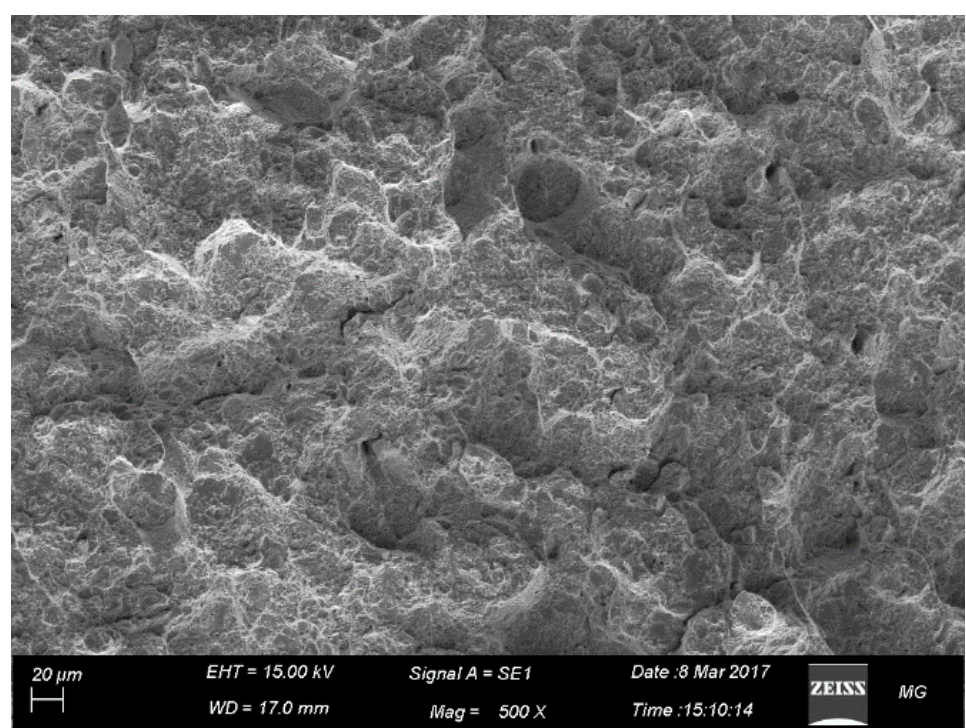

Fig.10 Tensile fracture surface of oil quenched specimens

The applications of spring steels in automotive industry require the ability of spring to absorb energy and withstand cyclic loads applied on it. So oil quenching is more convenient than water quenching, for spring steels, due to the effect of oil quenching on providing reasonable ductility and toughness with enough high strength [14].

\section{Effect of Tempering Parameters on the Mechanical Properties}

Fig.11 illustrates the effect of tempering temperature, for various holding times, on ultimate tensile strength of $50 \mathrm{Cr} 3$ spring steel after quenching in oil from $870^{\circ} \mathrm{C}$. The measured values of ultimate tensile strength on standard specimens of this steel tempered at $250^{\circ} \mathrm{C}$ for $1 \mathrm{hr}$ indicates the occurrence of a limited drop of strength relative to the quenched state, this drop start to decrease monotonically up to $400^{\circ} \mathrm{C}$, Where it start to noticeably decrease up to $550^{\circ} \mathrm{C}$. At that temperature we can point out that a drop of about $30 \%$ of ultimate strength relative to the quenched state has occurred. Prolonged holding times at the indicated tempering temperatures, for 2 and $3 \mathrm{hrs}$ result in a decrease of ultimate tensile strength by only about $6.8 \%$ and $7.2 \%$ respectively. 


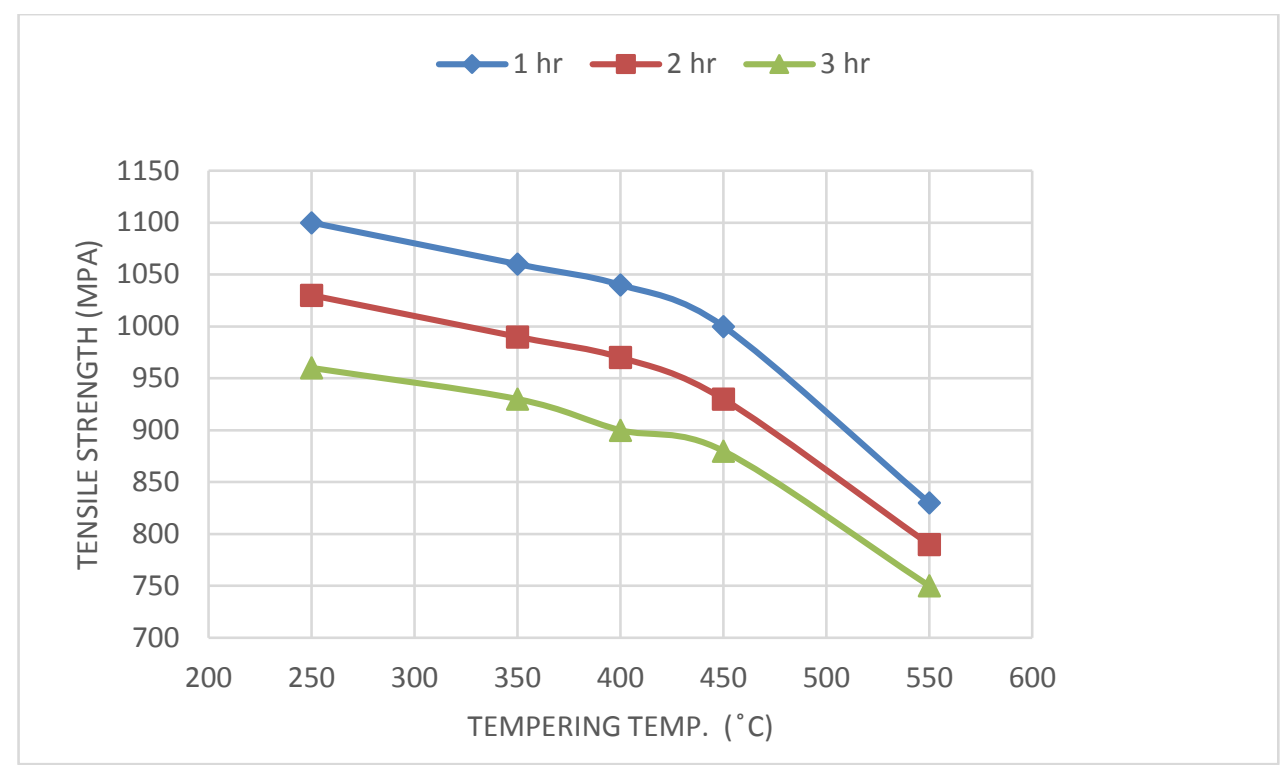

\section{Fig.11 Effect of tempering temperature, for various holding times, on ultimate tensile strength of $50 \mathrm{Cr} 3$ spring steel after quenching in oil from $870^{\circ} \mathrm{C}$.}

It was shown by $[15,16]$ that up to $200^{\circ} \mathrm{C}$, there is no major change in the morphology of lath martensite that have been formed during quenching and the limited diffusional processes allow partial relief of internal stresses, decrease of the density of dislocation inside the lathes, with reduction of martensitic tetragonality and formation of epsilon carbides $(\varepsilon)$. At higher temperatures up to $350^{\circ} \mathrm{C}$ retained austenite start to destabilize and provides bainite or ferrite carbide mixture. Starting from $400^{\circ} \mathrm{C}$ formation of cementite and chromium carbides takes place, and at further higher temperatures $\left(500^{\circ} \mathrm{C}\right.$ $550^{\circ} \mathrm{C}$ ) coarsening and spherodization manifested them self along with recovery and recrystallization of ferrite. This can explain the rapid drop of strength at temperature exceeding $400^{\circ} \mathrm{C}$.

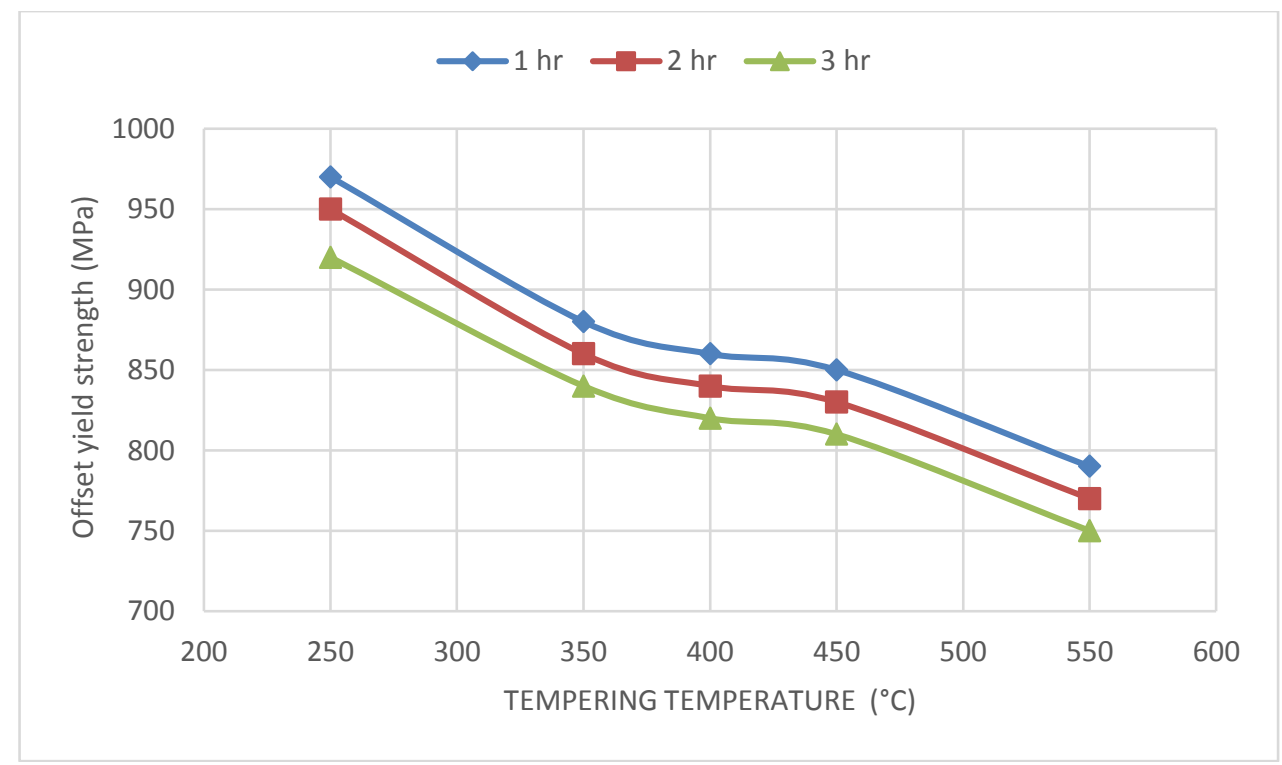

Fig. 12 Effect of tempering temperature, for various holding times, on offset yield strength of $50 \mathrm{Cr} 3$ spring steel after quenching in oil from $870^{\circ} \mathrm{C}$.

The effect of tempering temperature, for various holding times, on yield strength of $50 \mathrm{Cr} 3$ spring steel, after quenching in oil from $870^{\circ} \mathrm{C}$, is demonstrated in fig. 12 . We can remark the 
occurrence of a steady drop of yield strength, of about $12 \%$ relative to the offset yield strength of the quenched state, up to $350^{\circ} \mathrm{C}$.we can also clearly note that between 350 and $450^{\circ} \mathrm{C}$ the rate of drop is sensibly reduced and then it increases again above that range. This can be attributed to the mutual effect of destabilization and transformation of retained austenite to bainit and the dissolution of epsilon carbides $(\varepsilon)$ and formation of cementite and chromium carbides [17]. It worth also mentioning that the prolongation of holding time, at all tempering temperatures, results in modest decrease of the corresponding offset yield strength by only about $2 \%$.

Fig.13 elucidate the effect of tempering temperature, for various holding times, on the ductility (percentage elongation) of $50 \mathrm{Cr} 3$ spring steel after quenching in oil from $870^{\circ} \mathrm{C}$. From this diagram we can indicate that ductility is distinctly increased by increasing tempering temperature. For specimens tempered at different tempering temperatures, for $1 \mathrm{hr}$ holding time, we can report an increase of about $17 \%$ and $37 \%$ of ductility at temperatures $350^{\circ} \mathrm{C}$ and $550^{\circ} \mathrm{C}$ respectively, relative to the quenched state. We can also clearly note that, the same phenomenon which was observed on the previous fig. 12 , showing the effect of tempering temperature on the yield strength, also manifests on ductility between $350^{\circ} \mathrm{C}$ and $550^{\circ} \mathrm{C}$. In this range of temperature a net slowing down of the rate of increase of the ductility of this spring steel was observed and can also be attributed to the retained austenite transformation and cementite formation in this range. It also ultimately important to mentioned that any heat treatment has virtually no effect on the modulus of elasticity of this alloy at room temperature [18].

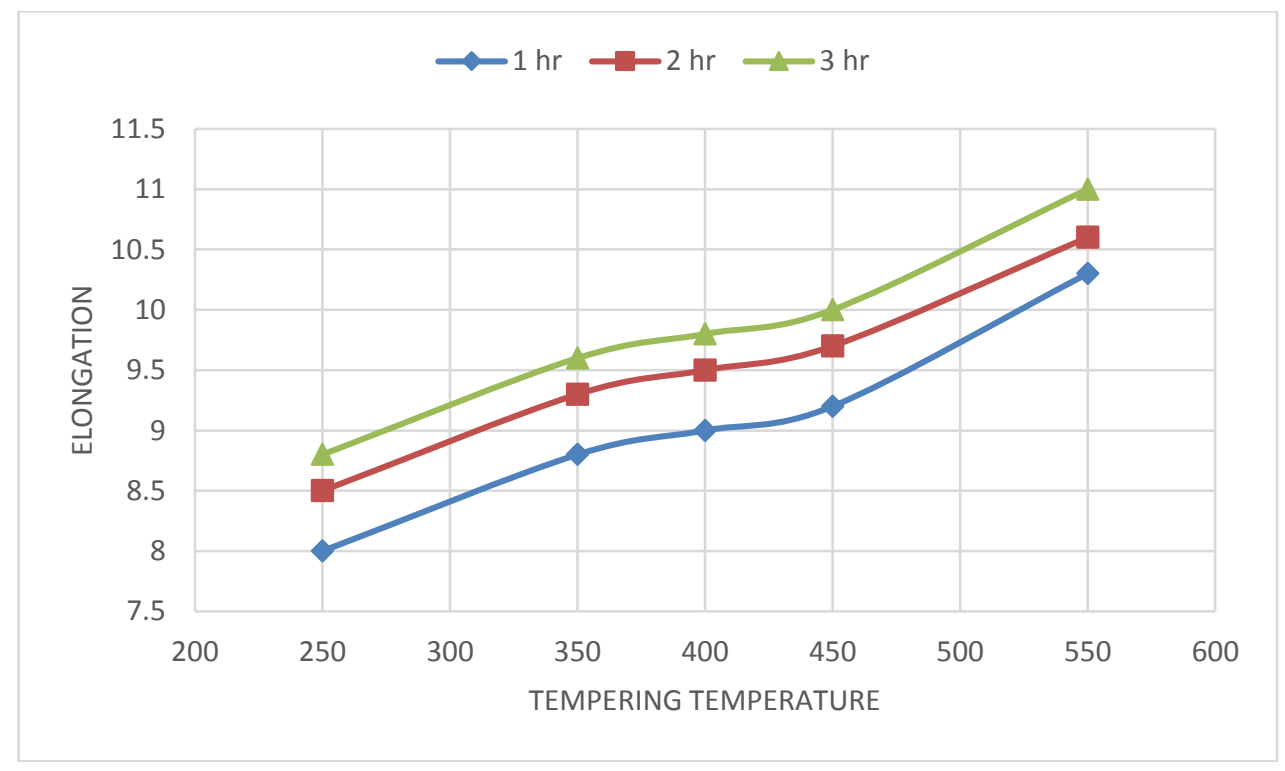

Fig.13 Effect of tempering temperature, for various holding times, on the ductility (percentage elongation) of $50 \mathrm{Cr} 3$ spring steel after quenching in oil from $870^{\circ} \mathrm{C}$.

The effect of tempering temperature, for various holding times, on Hardness values (HRC) of $50 \mathrm{Cr} 3$ spring steel after quenching in oil from $870^{\circ} \mathrm{C}$ is shown Fig. 14. The evolution of hardness with increasing the tempering temperature is very similar to that observed for offset yield strength shown in Fig.12. Relative to the quenched state the hardness drops by about $9 \%$ when tempering is carried out for $1 \mathrm{hr}$ at $350^{\circ} \mathrm{C}$ while it drops by about $31 \%$ when tempering is carried out at 550 for the same holding time. Prolonging the holding times at different tempering temperature has also similar effect of decreasing hardness. 


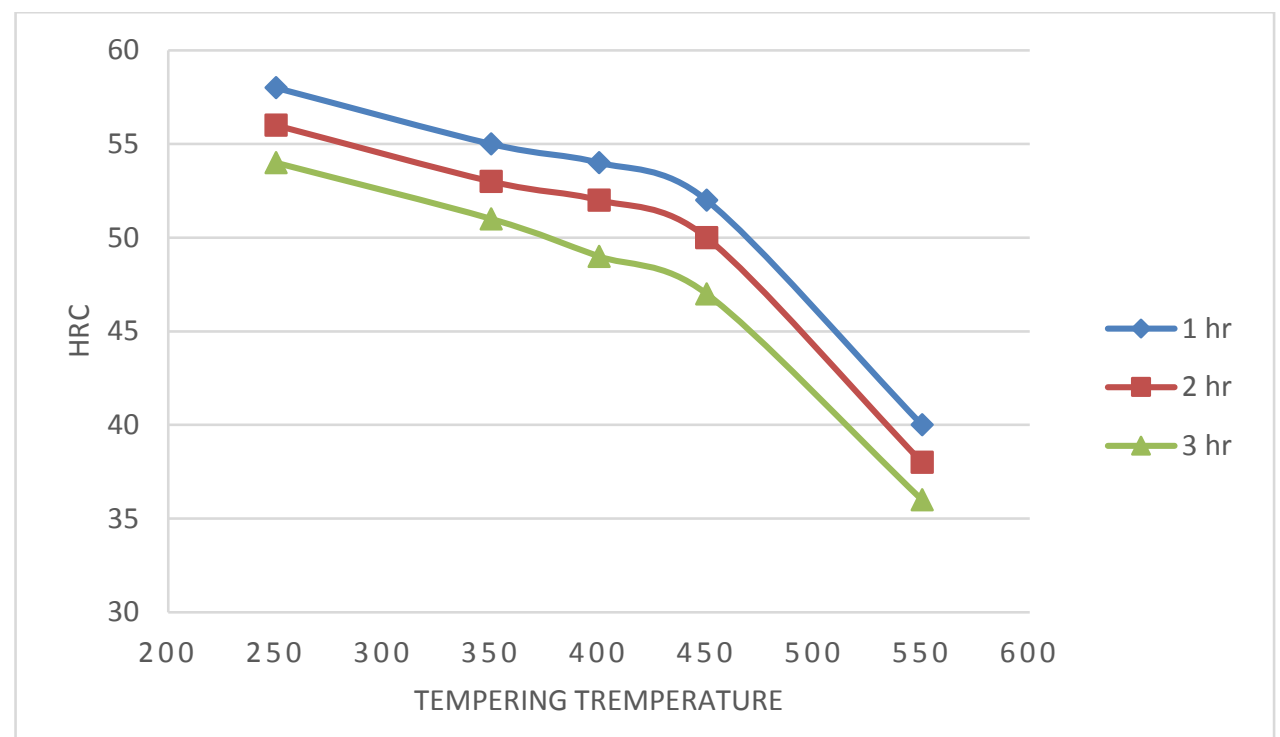

Fig. 14 Effect of tempering temperature, for various holding times, on Hardness (HRC) of $50 \mathrm{Cr} 3$ spring steel after quenching in oil from $870^{\circ} \mathrm{C}$.

D. Effect of Tempering Parameters on the Microstructure

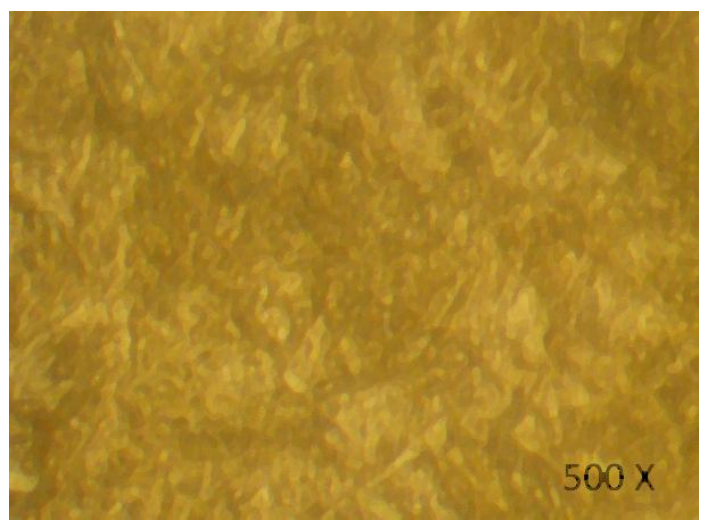

Fig.15 Microstructure of DIN 50Cr3 spring Steel after Oil Quenching from $870^{\circ} \mathrm{C}$ for $1 \mathrm{hr}$

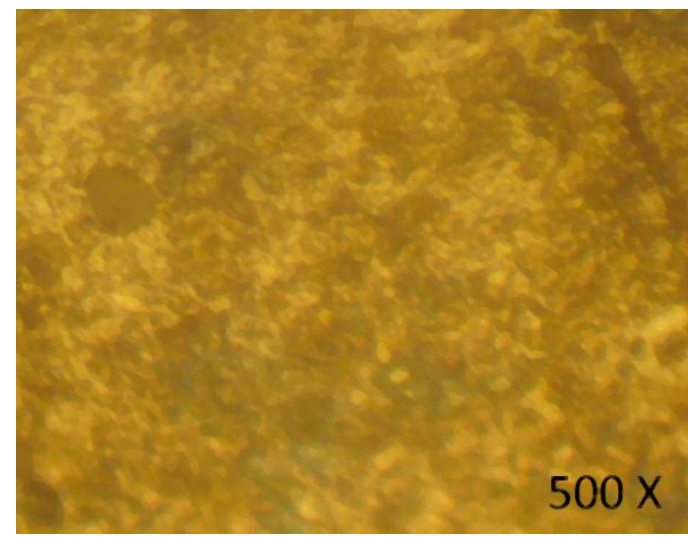

Fig 16 Microstructure of DIN $50 \mathrm{Cr} 3$ spring Steel tempered at $250^{\circ} \mathrm{C}$ for $1 \mathrm{hr}$

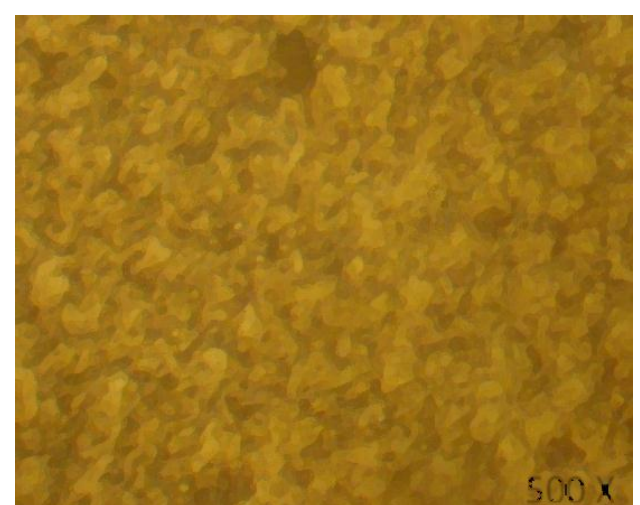

Fig 17 Microstructure of DIN 50Cr3

Steel tempered at $350^{\circ} \mathrm{C}$ for $1 \mathrm{hr}$ 


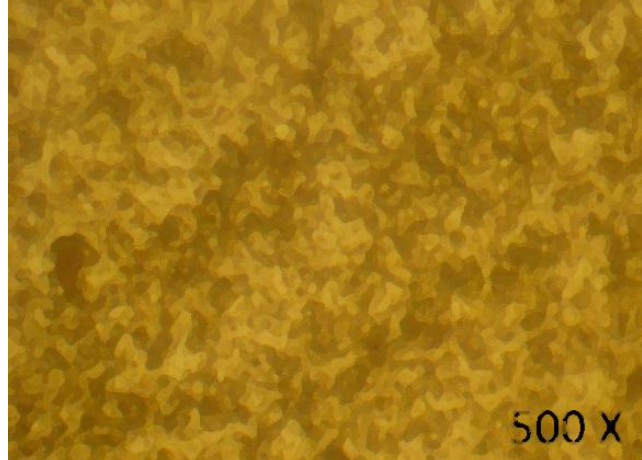

Fig 18 Microstructure of DIN $50 \mathrm{Cr} 3$ spring steel tempered at $450^{\circ} \mathrm{C}$ for $1 \mathrm{hr}$

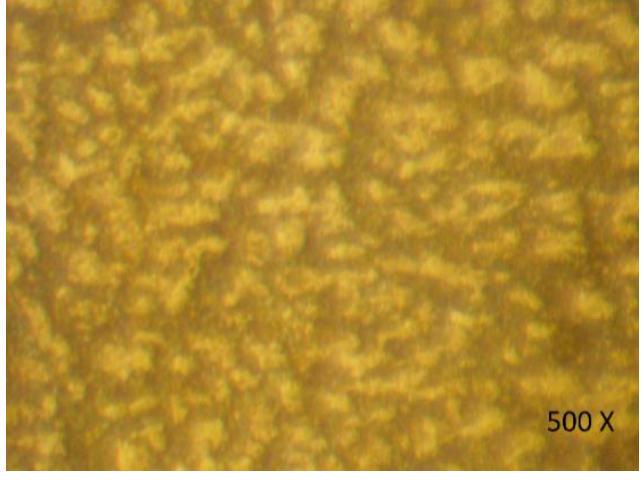

Fig 19 Microstructure of DIN 50Cr3 steel tempered at $550^{\circ} \mathrm{C}$ for $1 \mathrm{hr}$

Fig.15 illustrates the microstructure obtained on $50 \mathrm{Cr} 3$ spring steel after austenitization at $870^{\circ} \mathrm{C}$ for $1 \mathrm{hr}$ and quenching in oil. This structure is characterized by the existence of dominating phase of lath martensite and retained austenite. On the other hand, Figs. 16, 17, 18, 19 show the evolution of this microstructure with tempering temperature, where tempered martensite, bainite and carbides can observed. At high tempering temperature $\left(550^{\circ} \mathrm{C}\right)$ coarsening and recrystallization of ferrite can be visualized.

For spring steels to provide the essential requirements needed for their applications, in the various domains, they have to possess enough high hardness and strength with reasonable ductility and toughness, moreover, they should provide an ultimate elastic range, which can be obtained by the achievement of enough high ratio between their offset yield strength and ultimate strength $\left(\sigma_{0.2} / \sigma \mathrm{u}\right)$ [19]. For this type of spring steel (DIN $\left.50 \mathrm{Cr} 3\right)$, tempering at $450^{\circ} \mathrm{C}$ for $1 \mathrm{hr}$, can satisfy these requirements then this tempering parameters is consider the optimum parameters, which can be applied to impart the utmost mechanical properties for this spring steel. The tensile fracture surface obtained on specimens tempered at $450^{\circ} \mathrm{C}$ for $1 \mathrm{hr}$ is shown in Fig.20. The observation of the fracture surface shows that necking has taken place during tensile loading. The typical ductile 'cup and- cone' fracture surface includes two regions: the fiber region in the center and the outside shear lip have been obtained [20]. This indicates that under these optimum tempering conditions this spring steel can own enough high ductility and toughness with still high strength and hardness.
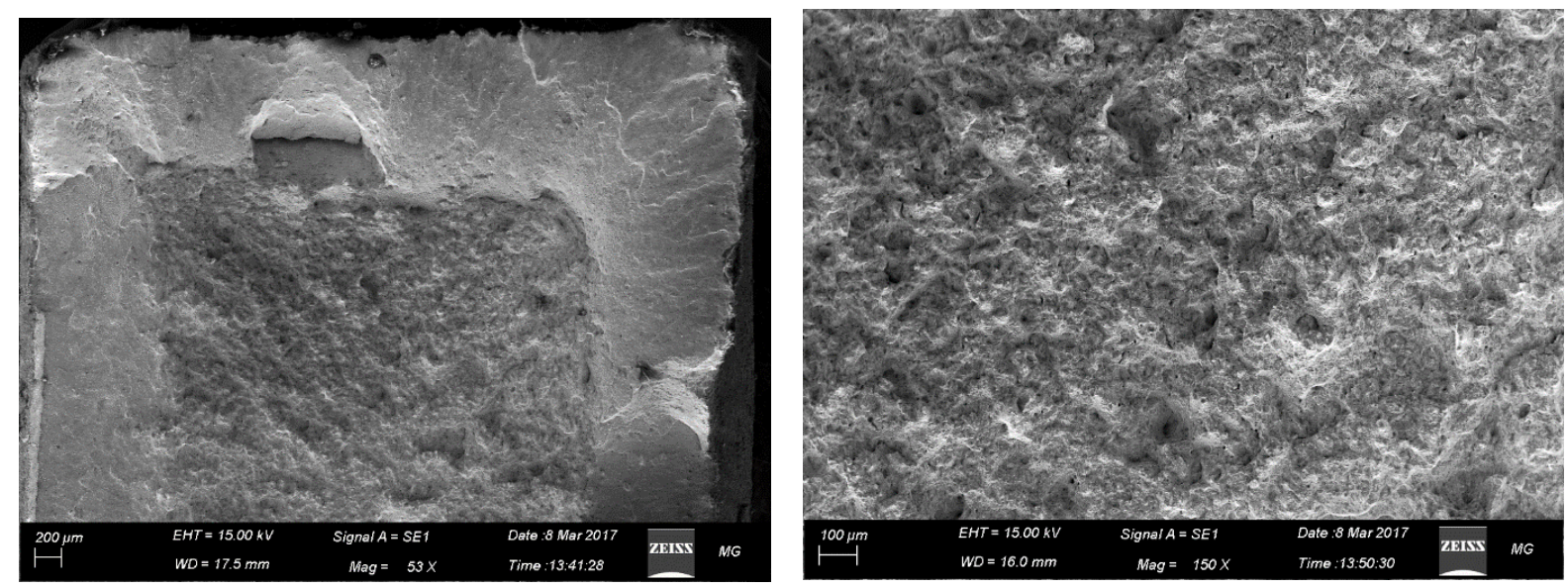

Fig. 20 Fracture surface of DIN 50Cr3 spring steel after oil quenching and tempering at $450^{\circ} \mathrm{C}$ for $1 \mathrm{hr}$ 


\section{Conclusions}

The following conclusion has been drawn from the experimental result and discussion:

- The proper austenitization temperature for the spring steel DIN $50 \mathrm{Cr} 3$ is $870{ }^{\circ} \mathrm{C}$.

- Oil quenching is more convenient than water quenching, for spring steels, due to the effect of oil quenching on providing reasonable ductility and toughness with enough high strength.

- Gradual decrease in hardness, ultimate tensile strength and increase in percent elongation of the as quench steel has been observed by increasing tempering temperature and time.

- Optimum mechanical properties and elastic properties for this type of spring steel (DIN $50 \mathrm{Cr} 3$ ) can be obtained after tempering at a temperature of $450^{\circ} \mathrm{C}$ for $1 \mathrm{hr}$.

\section{References}

[1] Wilson D V, Russel B., 1960, "The contribution of precipitation to strain ageing in low carbon steels", Acta Metallurgica, Vol 8, pp 468-479.

[2] Farrell R.M., \& T. S. Tyre, 1970, "The relationship between load and sliding distance in the initiation of mild wear of steel”, Journal of Wear, Vol 15, pp 359-372.

[3] Ahmed E, Priestner R., 1998, "Effect of rolling in the intercritical region on the tensile properties of dual phase steel”, Journal of Materials Engineering Performance, Vol 6, pp 772-776

[4] Erdogan M, Priestner R., 2002, "Effect of martensite content, its dispersion, and epitaxial ferrite content on Bauschinger behaviour of dual phase steel", Journal of Materials Science Technology, Vol 18, pp 369-376.

[5] Hozumi Goto \& Yoshufumi Amamoto, 2003, "Effect of varying load on wear resistance of carbon steel under unlubricated conditions", Journal of Wear, Vol 254, pp 1256-1266.

[6] Ng a* D.H.L., Cho a K.S., Wong a M.L., Chan b S.L.I., Mac X.-Y. , Lo d C.C.H., 2003, "Study of microstructure, mechanical properties and magnetization process in low carbon steel bars by Barkhausen emission”, Elsevier Journal, Materials Science and Engineering, A358, pp 186-198.

[7] Prof (Dr) Mitra P K, Dr. Paul S, Chatterjee S, 2004, "Treatment, Structure, Corrosion, Correlation of AISI 8640 Steel”, IE (I) Journal MM, Vol 85, pp 78-91.

[8] Woldman's engineering alloys, John. P. Frick, ASM International, 01-Jan-2000 Technology \&Engineering.

[9] A. I. Kulikov, "A New Quenching Medium for Metals and Alloys," Metal Science and Heat Treatment, Vol. 39, No. 11-12, 1997, pp. 528-530. Doi: 10.1007/BF02471373

[10] Larour P, Verleysen P. Bleck, W., 2006, "Influence of uniaxial, biaxial and plane strain pre-straining on the dynamic tensile properties of high strength sheet steels", Eighth international

[11] ASTM standard for materials.

[12] Dieter, G. E. 1998. Mechanical Metallurgy. Cambridge: McGraw-Hill Book.

[13] Bandyopadhyay N, McMahon C. The micro-mechanisms of tempered martensite embrittlement in 4340 type steels. Metall Trans A 1983; 14A:1313-25.

[14] Singh, V. 1998. "Heat Treatment of Metals". Delhi: Standard Publishers Distributors.

[15] D. Schreiber, I. Wiesenecker-Krieg, in: Verein Deutscher Eisenh"uttenleute (Ed.), Steel, A Handbook for Materials Research and Engineering, vol. 2, Springer Verlag and Verlag Stahleisen, Berlin and D"usseldorf, 1993, pp. 468-477.

[16] G. Krauss, C.J. McMahon Jr., in: G.B. Olson, W.S. Owen (Eds.), Martensite, ASM International, USA, 1992, pp. 295-321.

[17] W.F. Brown Jr., Aerospace Structural Materials handbook, code 1224, Metals and Ceramics information centre, (1989). 10.1016/b978-0-12-341829-6.50004-9 
[18] S.K. Banerji, C.J. McMahon Jr., H.C. Feng, Metall. Trans. A 9A (1978) 237-247.

[19] C.S. Smith, Trans. ASM 45 (1953) 533-573.

[20] T. Furuhara, S. Takagi, H. Watanabe, T. Maki, Metall. Mater. Trans. 27A (1996) 16351646. 